PREPARED FOR THE U.S. DEPARTMENT OF ENERGY, UNDER CONTRACT DE-AC02-76CH03073

PPPL-3719

PPPL-3719

UC-70

Kinetic Stability of the Field Reversed Configuration

by

E.V. Belova, R.C. Davidson, H. Ji, and M. Yamada

July 2002

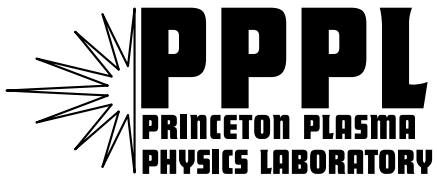

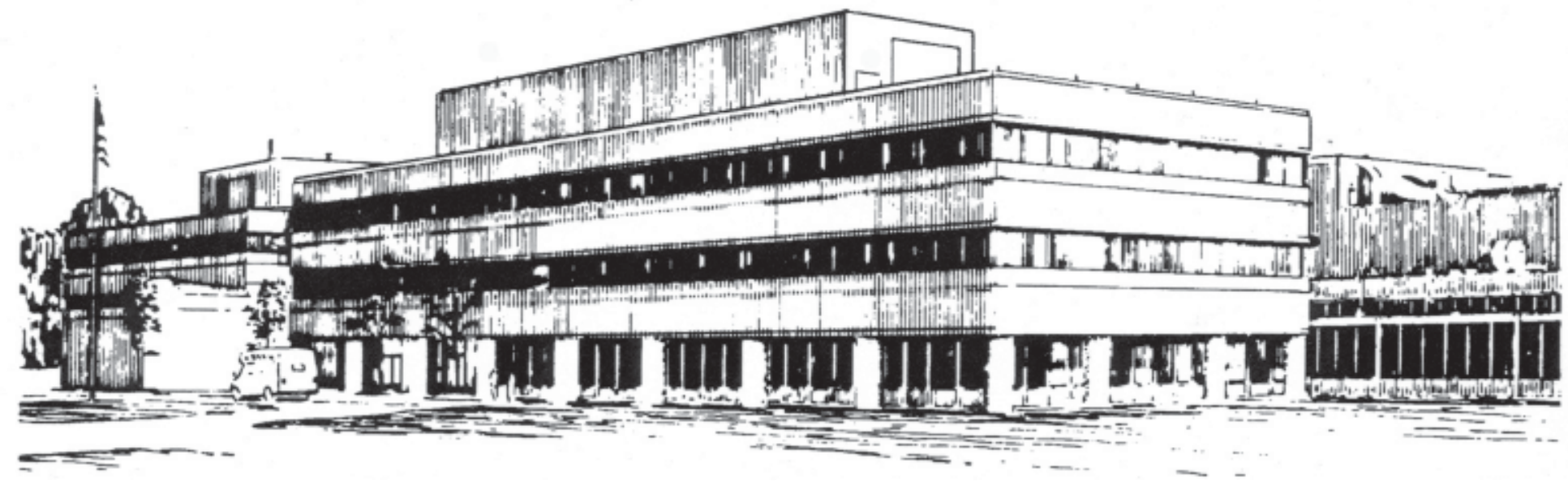

PRINCETON PLASMA PHYSICS LABORATORY PRINCETON UNIVERSITY, PRINCETON, NEW JERSEY 


\section{PPPL Reports Disclaimer}

This report was prepared as an account of work sponsored by an agency of the United States Government. Neither the United States Government nor any agency thereof, nor any of their employees, makes any warranty, express or implied, or assumes any legal liability or responsibility for the accuracy, completeness, or usefulness of any information, apparatus, product, or process disclosed, or represents that its use would not infringe privately owned rights. Reference herein to any specific commercial product, process, or service by trade name, trademark, manufacturer, or otherwise, does not necessarily constitute or imply its endorsement, recommendation, or favoring by the United States Government or any agency thereof. The views and opinions of authors expressed herein do not necessarily state or reflect those of the United States Government or any agency thereof.

\section{Availability}

This report is posted on the U.S. Department of Energy's Princeton Plasma Physics Laboratory Publications and Reports web site in Fiscal Year 2002. The home page for PPPL Reports and Publications is: http://www.pppl.gov/pub_report/

DOE and DOE Contractors can obtain copies of this report from:

U.S. Department of Energy

Office of Scientific and Technical Information

DOE Technical Information Services (DTIS)

P.O. Box 62

Oak Ridge, TN 37831

Telephone: (865) 576-8401

Fax: (865) 576-5728

Email: reports@adonis.osti.gov

This report is available to the general public from:

National Technical Information Service

U.S. Department of Commerce

5285 Port Royal Road

Springfield, VA 22161

Telephone: 1-800-553-6847 or

(703) 605-6000

Fax: (703) 321-8547

Internet: http://www.ntis.gov/ordering.htm 
29th EPS Conference on Plasma Physics and Controlled Fusion

17-21 June 2002, Montreux Switzerland

\title{
Kinetic Stability of the Field Reversed Configuration
}

\author{
E. V. Belova, R. C. Davidson, H. Ji, M. Yamada \\ Princeton Plasma Physics Laboratory, P. O. Box 451, Princeton, NJ 08543, USA
}

New computational results are presented which advance the understanding of the stability properties of the Field-Reversed Configuration (FRC). The FRC is an innovative confinement approach that offers a unique fusion reactor potential because of its compact and simple geometry, translation properties, and high plasma beta. One of the most important issues is FRC stability with respect to low- $n$ (toroidal mode number) MHD modes. There is a clear discrepancy between the predictions of standard MHD theory that many modes should be unstable on the MHD time scale, and the observed macroscopic resilience of FRCs in experiments.

We have developed a 3D nonlinear hybrid and MHD simulation code (HYM) [1] to investigate a variety of non-ideal MHD effects, including plasma flow and kinetic effects on FRC stability properties, particularly with respect to the $n=1$ tilt mode. Previous calculations demonstrated a significant reduction in the linear growth rates in prolate FRCs with $E \gtrsim 4$ due to kinetic effects [1,2], and a nonlinear saturation of instabilities for $\bar{s} \lesssim 2$ [3], where $E$ is the separatrix elongation, and $\bar{s}$ is a kinetic parameter which measures the number of thermal ion gyro-radii in the configuration. No absolute linear stability was found even in the highly kinetic regime $(\bar{s}<1)[1]$. We present new results of hybrid and two-fluid (Hall-MHD) simulations of prolate FRCs with $E=4-8$ and $\bar{s}=1-8$. The instability mechanisms at low $\bar{s}$ and the nonlinear evolution of unstable modes for larger values of $\bar{s}$ are investigated, as well as the effects of the particle loss along the open field lines, and Hall stabilization.

Analysis of particle trajectories for small $\bar{s}$ demonstrates the existence of a significant fraction of regular-orbit ions. These ions can be in betatron resonance [4] with MHD modes, in particular with the $n=1$ mode, maintaining the tilt instability in the large gyroradius regime, beyond the FLR stabilization threshold. Simulation results for $\bar{s}=0.8$ racetrack separatrix shape and $E=7$ (Fig. 1) show that a relatively small fraction (about 4\%) of resonant particles 
contributes significantly to the energy balance, and is important for the instability drive. The unstable mode is a negative energy wave, which propagates in the direction opposite to the equilibrium current (in the ion frame) with the phase velocity smaller than the ion diamagnetic velocity. It is also found that the fraction of regular orbits versus stochastic orbits in FRC depends strongly on the separatrix shape and elongation.

The nonlinear saturation, observed at low $\bar{s}$ [3], occurs due to the nonlinear deviation of the ion distribution function from a local Maxwellian. The unstable configuration evolves nonlinearly into a new equilibrium with smaller $\bar{s}$, larger $E$ and the increased separatrix beta. The nonlinear stabilization of the $n=1$ tilt mode explains the observation in the low $\bar{s}$ experiments of initial $n=1$ tilt motion that does not result in total loss of confinement. However, the reported FRC stability for larger values of $\bar{s}(\bar{s} \gtrsim 4)$ has not been explained so far.

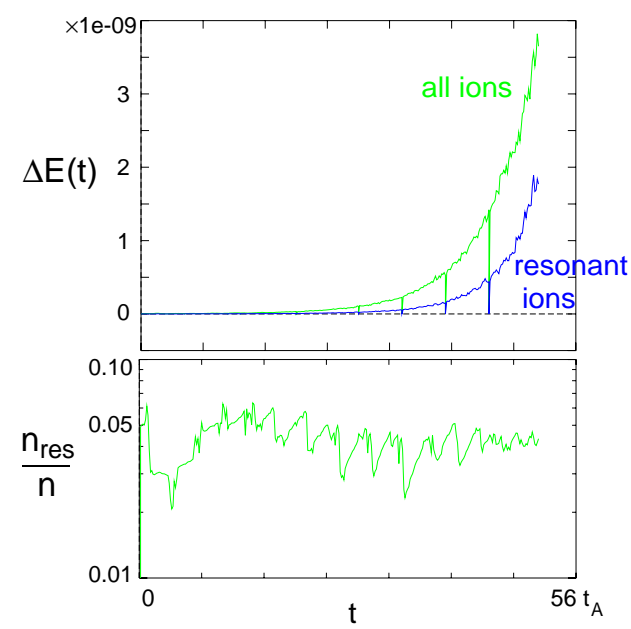

Figure 1: Kinetic energy (a), and fraction of resonant ions (b) from simulations of $n=1$ tilt mode with $E=7$ and $\bar{s}=0.8$.

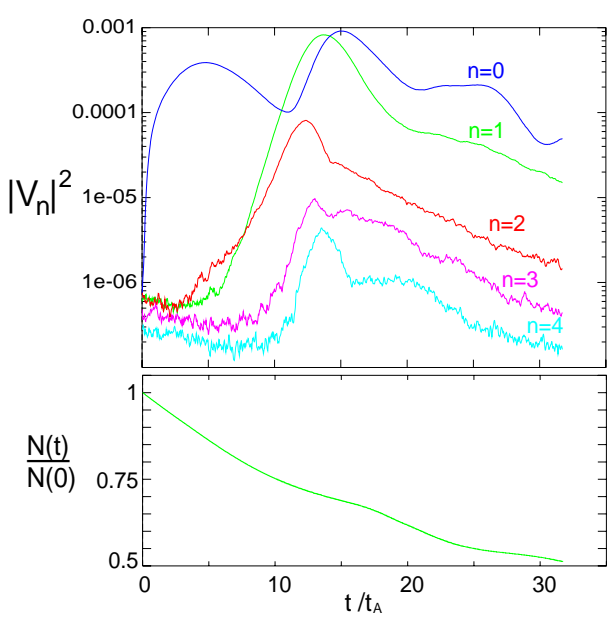

Figure 2: Energy plots for $n=0-4$ modes (a), and total number of particles (b) from simulations with $E=4$ and $\bar{s}=7.4$.

Our hybrid simulations with loss boundary conditions (Fig. 2) and larger values of $\bar{s}$ (small gyroradius regime) show a significant loss of particles (about $30 \%$ ) during the linear phase of the instability. Particle loss along the open field lines has a destabilizing effect on the $n=1$ tilt mode, increasing the linear growth rate by $\approx 10 \%$ compared to simulations with periodic boundary conditions. The increase in the growth rate is related to the reduction of the separatrix beta and the plasma pressure outside the separatrix. 
In the large $\bar{s}$ simulations, the linear growth rate of the $n=1$ tilt mode is very close to that of the MHD with $\gamma \gtrsim 0.9 \gamma_{m h d}$, and the nonlinear saturation does not occur. However, the observed nonlinear evolution is considerably slower than that in the MHD simulations. Thus, despite the loss of about half of the particles, a field reversal of $B_{z} \approx-0.5 B_{\text {ext }}$ is still present by $t=32 t_{A}$ in the simulations shown in Fig. 2. Significant ion spin up in toroidal (diamagnetic) direction is also observed at $t>20 t_{A}$ with $V_{i} \approx 0.3 v_{A}$, which agrees well with experiments. The slow nonlinear evolution found in the kinetic simulations is probably related to the reduction of the effective value of $\bar{s}$ during the nonlinear phase on the instability, after a significant fraction of internal flux is lost. Both the reduction of $\bar{s}$ and the ion spin-up can have a stabilizing effect on the instability, extending the FRC life-time to $t \gtrsim 30 t_{A}$. In contrast, the MHD simulations show a rapid FRC disruption in about $\approx 10 t_{A}$. Since end mirror coils are likely to improve particle confinement and further slow down the nonlinear evolution, our large- $\bar{s}$ nonlinear results potentially can provide an explanation of the observed FRC behavior for $\bar{s}>4$ cases.

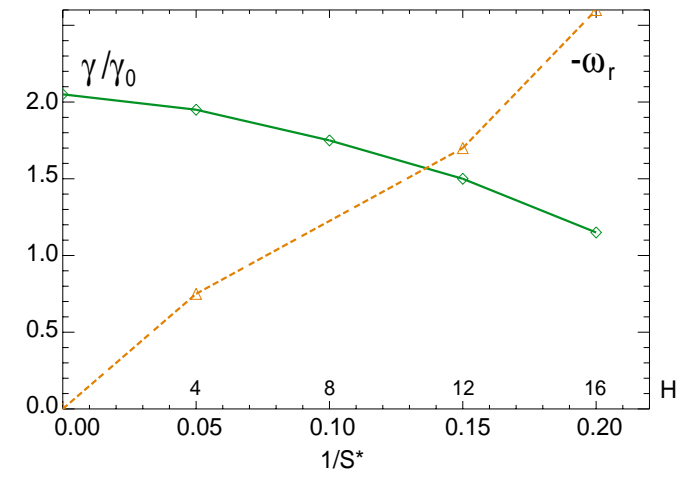

Figure 3: Growth rate and real frequency of the tilt mode from Hall-MHD simulations with $E=6$.

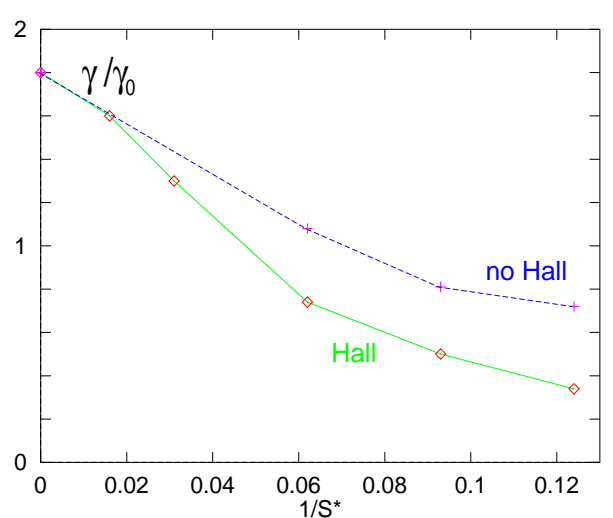

Figure 4: Growth rate of the tilt mode from hybrid simulations with Hall term (solid line) and without Hall term (dashed line) for $E=4$.

In order to assess the importance of different stabilizing factors on the FRC stability properties, we have performed two-fluid (Hall-MHD) simulations of the $n=1$ tilt mode. The MHD version of HYM code has been modified to include the Hall term in the Ohm's law, and sub-cycling in the induction equation has been used to insure the numerical stability. Calculations with $E=6$ and elliptical separatrix shape show a reduction of the tilt mode 
growth rate for small $\bar{s}$ (Fig. 3) and a significant change in the mode structure (Fig. 5). The unstable mode has a negative real frequency, and propagates in the direction opposite to that of the equilibrium current. The reduction in the linear growth rate by a factor of two for $S^{*} / E \sim 1\left(S^{*} \approx 5-8 \bar{s}\right)$ due to Hall stabilization is not sufficient to explain the stability, and therefore, finite Larmor radius and other kinetic effects are also important.

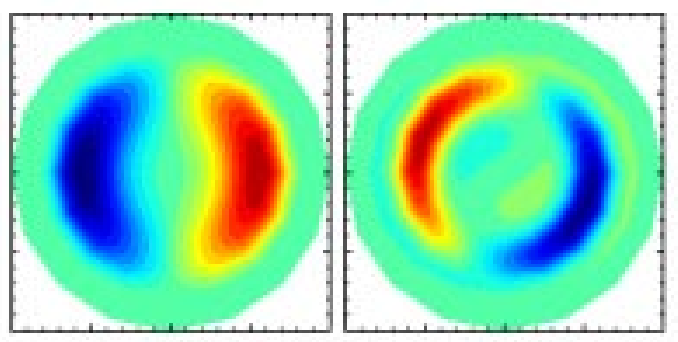

Figure 5: Linear mode structure from (a) MHD, and (b) Hall-MHD simulations with $S^{*}=5$ and $E=6$.

In addition, we have performed hybrid simulations for $E=4$ and elliptic separatrix shape both including Hall term in the Ohm's law, and without it. A similar reduction in the linear growth rate due to Hall effect has been found (Fig. 4). A comparison of the results of the Hall-MHD and hybrid simulations with and without Hall term have shown that the Hall term is responsible for the mode rotation in the negative direction and the change in the linear mode structure, however, the reduction in the growth rate is mostly due to finite Larmor radius effects. Our numerical simulations have demonstrated that a combination of kinetic and nonlinear effects is essential for explaining the experimentally observed FRC behavior.

\section{References}

[1] E.V. Belova et al., Phys. Plasmas 7, 4996 (2000); 8, 1267 (2001).

[2] D. C. Barnes et al., Phys. Fluids 29, 2616 (1986).

[3] E.V. Belova et al., Plasma Physics and Controlled Nuclear Research, Proceedings of the 18th International Conference, Sorrento 2000 (International Atomic Energy Agency, Vienna, 2000).

[4] J. M. Finn and R. N. Sudan, Phys. Fluids 22, 1148 (1979).

This work is supported by US DOE. 


\section{External Distribution}

Plasma Research Laboratory, Australian National University, Australia

Professor I.R. J ones, Flinders University, Australia

Professor J oão Canalle, Instituto de Fisica DEQ/IF - UERJ , Brazil

Mr. Gerson O. Ludwig, Instituto Nacional de Pesquisas, Brazil

Dr. P.H. Sakanaka, Instituto Fisica, Brazil

The Librarian, Culham Laboratory, England

Library, R61, Rutherford Appleton Laboratory, England

Mrs. S.A. Hutchinson, JET Library, England

Professor M.N. Bussac, Ecole Polytechnique, France

Librarian, Max-Planck-Institut für Plasmaphysik, Germany

J olan Moldvai, Reports Library, MTA KFKI-ATKI, Hungary

Dr. P. Kaw, Institute for Plasma Research, India

Ms. P.J . Pathak, Librarian, Insitute for Plasma Research, India

Ms. Clelia De Palo, Associazione EURATOM-ENEA, I taly

Dr. G. Grosso, Instituto di Fisica del Plasma, Italy

Librarian, Naka Fusion Research Establishment, J AERI, J apan

Library, Plasma Physics Laboratory, Kyoto University, J apan

Research Information Center, National Institute for Fusion Science, J apan

Dr. O. Mitarai, Kyushu Tokai University, J apan

Library, Academia Sinica, Institute of Plasma Physics, People's Republic of China

Shih-Tung Tsai, Institute of Physics, Chinese Academy of Sciences, People's Republic of China

Dr. S. Mirnov, TRINITI, Troitsk, Russian Federation, Russia

Dr. V.S. Strelkov, Kurchatov Institute, Russian Federation, Russia

Professor Peter Lukac, Katedra Fyziky Plazmy MFF UK, Mlynska dolina F-2, Komenskeho Univerzita, SK-842 15 Bratislava, Slovakia

Dr. G.S. Lee, Korea Basic Science Institute, South Korea

Mr. Dennis Bruggink, Fusion Library, University of Wisconsin, USA

Institute for Plasma Research, University of Maryland, USA

Librarian, Fusion Energy Division, Oak Ridge National Laboratory, USA

Librarian, Institute of Fusion Studies, University of Texas, USA

Librarian, Magnetic Fusion Program, Lawrence Livermore National Laboratory, USA

Library, General Atomics, USA

Plasma Physics Group, Fusion Energy Research Program, University of California at San Diego, USA

Plasma Physics Library, Columbia University, USA

Alkesh Punjabi, Center for Fusion Research and Training, Hampton University, USA

Dr. W.M. Stacey, Fusion Research Center, Georgia Institute of Technology, USA

Dr. J ohn Willis, U.S. Department of Energy, Office of Fusion Energy Sciences, USA

Mr. Paul H. Wright, Indianapolis, Indiana, USA 
The Princeton Plasma Physics Laboratory is operated by Princeton University under contract with the U.S. Department of Energy.

\author{
Information Services \\ Princeton Plasma Physics Laboratory \\ P.O. Box 451 \\ Princeton, NJ 08543
}

Phone: 609-243-2750

Fax: 609-243-2751

e-mail: pppl_info@pppl.gov

Internet Address: http://www.pppl.gov 